DOI 10.14746/ssp.2019.4.3

Надежда ТорховА

Черноморский национальный университет имени Петра Могилы

(г. Николаев, Украина)

\title{
Управление связями с общественностью в судах Украины как многоаспектный комплексный процесс
}

\begin{abstract}
Аннотация: В статье исследованы теоретические и практические основы управления связями с общественностью в судах Украины, нуждающихся в повышении уровня доверия граждан, более прозрачного освещения своей деятельности в условиях реформ.

Автор освещает управление связями с общественностью в органах правосудия Украины как многоаспектный комплексный процесс, который включает в себя организацию коммуникационного подразделения и повышение квалификации его работников, определение потребностей целевых групп общественности на основе составления профиля ценностей, стратегическое планирование коммуникативной деятельности, применение программ охвата и методологии карточек гражданского отчетности.

В статье сформулировано определение понятия связей с общественностью в органах правосудия с учетом специфики судебной системы, диагностированы проблемы в сфере организации связей с общественностью в судебной системе, даны рекомендации для создания действенной системы связей с общественностью в органах публичного управления.
\end{abstract}

Ключевые слова: управление, суд, связи с общественностью

\section{Введение}

O дной из важных функций в системе публичного управления и администрирования есть связи с общественностью - успешная реализация этой управленческой функции способствует развитию гражданского общества и демократизации его институтов. Учитывая это, концепция переформатирования моделей управления сферой связей с общественностью в органах государственной власти относится к современным представлениям о реформирова- 
нии системы органов публичного управления в Украине. Ученые по этому поводу справедливо отмечают, что «становление новой парадигмы государственного управления возможно через призму коммуникативного менеджмента», поскольку именно эта концепция может максимально эффективно способствовать решению вопросов государственного уровня (Arkhypova, Dmytrenko, 2016, c. 94).

Проблема формирования эффективных связей с общественностью и со средствами массовой информации приобретает особую актуальность для украинских судов из-за того, что последние до сих пор имеют низкий авторитет среди населения, неудовлетворительный уровень информационной открытости и прозрачности. Долгое время судебная система существовала в максимально закрытом информационном пространстве, что было обусловлено историческими реалиями и привело к некоторому дистанцированию от общества и потери его доверия. Это подтверждают данные социологических исследований. Так, по результатам общенационального опроса, который с 7 по 14 февраля 2019 провела социологическая служба Украинского центра экономических и политических исследований имени Александра Разумкова, лишь 12\% граждан доверяют судам (Zvit za rezultatamy doslidzhennia, 2019, р. 50). Показатели масштабного исследования, которое провели эксперты ОО «Бюро правовых коммуникаций» в 2018-2019 годах, доказали, что только 11 судов (из 675 исследованных) имели высокий общий рейтинговый индекс информационной открытости в 2018 году (7-8 баллов по десятибалльной шкале) (Reitynh informatsiinoi vidkrytosti sudiv, 2019).

Указанные объективные причины обусловливают необходимость освещения особенностей и проблем управления связями с общественностью в современных условиях осуществления судебной реформы. Поиск действенных способов реализации управленческой функции связей с общественностью в органах публичного управления, в частности в органах правосудия, для повышения уровня их открытости и прозрачности является перспективной научной проблемой, которая, несмотря на мощное развитие информационных и коммуникационных технологий, имеет достаточную степень глубины для исследований. 


\section{Процесс управления связями с общественностью в органах правосудия: внешний аспект}

Термин «связи с общественностью» или «паблик рилейшнз, PR» отождествляется и со сферой научных знаний, которая исследует эту деятельность, и с конкретными структурными подразделениями, взаимодействующими с общественностью. Все определения связей с общественностью освещают различные свойства этой деятельности, однако есть общая черта, отраженная во всех интерпретациях термина «паблик рилейшнз»: наличие взаимной коммуникации между организацией, предприятием, органом власти и общественностью.

В нашей статье внимание сосредоточено на внешнем аспекте управления паблик рилейшнз органа публичного управления. Учитывая это, цель связей с общественностью органа публичного управления определяем как содействие формированию общественного мнения, которое соответствует целям учреждения и следует из мотивов и ценностей органа власти. Итак, предметом паблик рилейшнз в органах публичного управления, по нашему мнению, является управление определенными ценностями, общественным мнением. Основой мотивов и ценностей органов государственного управления являются задачи, определенные в действующем законодательстве для каждого органа государственной власти.

Объектом управления в сфере паблик рилейшнз в органах государственной власти является общественность, на которую влияет орган власти с целью формирования позитивного общественного мнения. Поскольку в демократических государствах все чаще образуется активное взаимодействие между органом власти и общественностью и возникает обратная связь, объект во время совместной деятельности может быть превращен в субъект. Орган государственной власти должен выбирать объект управления в каждом конкретном случае, в зависимости от цели PR-мероприятия. Например, во время проведения правоведческой викторины в рамках Дня открытых дверей в органе судебной власти объектом управления (целевой аудиторией) будет выступать молодежь (школьники, студенты) (Ahafonova, 2018, с. 17).

Субъектом связей с общественностью является инициатор деятельности в сфере паблик рилейшнз. Субъектом PR-отношений 
между государством и обществом отношений являются органы государственной власти (законодательной, исполнительной, судебной), органы местного самоуправления. Сущность отношений органов власти с общественностью раскрывается через задачи этой деятельности, о перечне которых существует немало различных взглядов исследователей, но все они имеют в своей основе идею консенсуса (принятие консенсусных решений является частью процесса осуществления паблик рилейшнз).

В общем понимании связи с общественностью в органах государственной власти является управленческой функцией, способствующей организации коммуникации для выявления общих интересов и налаживания сотрудничества между органом публичного управления и общественностью. Отсюда вытекает одно из важных задач связей с общественностью - достижение и сохранение взаимопонимания и доверия, открытости и прозрачности, которые являются фундаментом транспарентности органа государственной власти.

Рассматривая управление связями с общественностью в судах Украины, считаем целесообразным уточнить содержание этой деятельности в судебной системе. Итак, под связями с общественностью в органах правосудия понимаем управленческую деятельность по организации и обеспечению функционирования модели многовекторной интерактивной коммуникации суда с общественностью и СМИ, которая предусматривает создание партнерского диалога на паритетных началах, но учитывает ряд ограничений, установленных в действующем законодательстве и связанных с реализацией гражданами процессуальных прав и доступом к определенной информации, что обусловлено спецификой суда как органа, осуществляющего правосудие и по закону являющегося независимым от любого внешнего воздействия.

Процесс управления связями с общественностью и СМИ в органах публичного управления проявляется в функционировании определенных организационных форм. Современная практика развития связей с общественностью и СМИ позволяет выбрать оптимальную форму в зависимости от характера деятельности организации, ее системы управления и задач, которые планируется решить при взаимодействии с целевыми аудиториями.

Наиболее популярный путь осуществления связей с общественностью в органах правосудия Украины на современном этапе - че- 
peз PR-специалиста в штате органа власти или через образованный в структуре органа власти отдел (подразделение, управление или) связей с общественностью, который имеет двойное подчинение в условиях закрепленного в законодательстве распределения управленческой деятельности - например, в органах судебной власти, пресс-секретарь обычно подотчетен и руководителю аппарата суда, и председателю суда.

В деятельности отдельного структурного подразделения (прессслужбы) и пресс-секретаря, который является единственным лицом, отвечающим за коммуникационную деятельность в суде, есть много общих признаков. Основное отличие заключается в том, что прессслужба имеет штат работников и большие организационные и технические возможности.

Коммуникационное подразделение (пресс-служба) - важная составляющая управленческой системы в органах публичного управления. Создание отдельных структурных подразделений для взаимодействия с общественностью и средствами массовой информации, пресс-служб позволяет наиболее полно реализовать потенциал управленческой функции паблик рилейшнз. Эффективная работа таких подразделений в органах правосудия является органической частью процесса повышения прозрачности и открытости суда, одним из действенных способов влияния на формирование общественного мнения.

Сейчас только в некоторых судах организована работа двух работников, которые выполняют функции пресс-службы. Наиболее популярной формой остается пресс-служба, которую олицетворяет один работник (пресс-секретарь или специалист по обеспечению связей с общественностью и СМИ).

Важные шаги для развития диалога между органами правосудия и обществом сделали Совет судей Украины и Высший совет правосудия: введение должностей пресс-секретарей в судах, создание Пресс-центра судебной власти. Однако эти меры не устранили потребности в системном подходе к управлению связями с общественностью на профессиональной основе. Анализ современного состояния организации и функционирования пресс-служб в органах правосудия Украины обнаружил круг проблем в администрировании: совмещение обязанностей пресс-секретаря (дополнительных) с другой (основной) деятельностью, двойное или несколько ступен- 
чатая подчинения, проблема взаимозаменяемости, спорадичность в работе с общественностью, проблемы планирования. Несмотря на существенные положительные сдвиги в сфере управления связями с общественностью в судах, вопросы повышения эффективности управления PR-структурами требуют научного осмысления и широкого обсуждения.

Анализ реализации управленческой функции связей с общественностью позволил сделать вывод: в судах, в которых количество работников превышает 40 человек, целесообразно создавать отдельное структурное подразделение, в структуре которого должно быть как минимум две должности - для лица, ответственного за связи с общественностью (за реализацию прямых связей с общественностью, за предоставление ответов на обращения граждан и по запросам на публичную информацию), и лица, ответственного исключительно за связи с прессой (пресс-секретаря). В то же время желательно, чтобы эти два работника могли взаимозаменять друг друга.

Создание коммуникационных подразделений требует хорошо подготовленных практиков в сфере связей с общественностью. Большинство специалистов в области паблик рилейшнз начали карьеру в этой сфере, имея образование по другим специальностям. Несмотря на успешное овладение некоторыми пресс-секретарями новыми знаниями, остается проблема с обеспечением надлежащей квалификации специалистов, занятых в сфере связей с общественностью в органах публичного управления.

В вопросе определения направления образования специалиста по обеспечению связей с общественностью, пресс-секретарей органа публичного управления, в частности суда, среди ученых, управленцев и юристов нет единодушия во взглядах на эту проблему. Ученые дискутируют относительно отнесения связей с общественностью в одной из отрасли наук - коммуникативных или управленческих.

В реальности, как правило, пресс-секретарь органа судебной власти имеет образование юридического направления, что позволяет ему четко понимать специфику работы суда и судебного процесса. В то же время работа в должности пресс-секретаря требует от последнего мультидисциплинарного комплекса знаний и высоко развитых навыков в области планирования, управления, аналитической работы, коммуникаций, журналистской работы и т.п. - такие 
умения и навыки специалист по обеспечению связей со средствами массовой информации должен получить в процессе специальной подготовки пресс-секретарей (курса повышения квалификации), разработка и внедрение которой должно обеспечить государство.

М. Вильгушинский отмечает, что работники суда требуют специальной подготовки, которая обеспечивает профессиональное информирование (Vilhushynskyi, 2014, с. 8). Эта мысль справедлива и в отношении других органов публичного управления, в которых на должностях пресс-секретарей часто работают представители различных специальностей.

При этом необходимо учесть, что специфика деятельности органа публичного управления детерминирует содержание профессиональной подготовки и направления повышения квалификации специалистов по обеспечению связей с общественностью и СМИ. Учет этого правила может гармонизировать процесс связей с общественностью. В то же время в программах по повышению квалификации специалистов по обеспечению связей с общественностью и СМИ необходимо предусмотреть унифицированные учебные модули, которые можно использовать в обучении специалистов любому органу публичного управления: 1) Правовой статус органа публичного управления; 2) Организация работы пресс-службы; 3) Статус пресс-секретаря; 4) Стратегическое планирование; 5) Исследование общественного мнения; 6) Общеобразовательные и в-правовые дисциплины; 7) Коммуникативные инструменты в работе суда. Прямые связи с общественностью; 8) Медиа-сопровождение деятельности суда; 9) Подготовка PR-текстов; 10) Практика применения профильного законодательства; 11) Антикризисный менеджмент; 12) Внутренняя коммуникация; 13) Продвижение в социальных сетях (основы SMM).

Такая программа имеет комплексный характер, сочетая элементы и академической, и журналистской, и бизнес-модели PRобразования. В этом контексте необходимо выделить, что в Украине до сих пор не существует специальной государственной программы подготовки пресс-секретарей органов государственной власти. Указанный набор модулей может удовлетворить потребности коммуникаторов и администраторов как суда, так и любого другого органа публичного управления в понимании как коммуникативных, так и управленческих процессов. 
Механизмы обеспечения взаимодействия органов публичного управления с общественностью имеют в основе своей модели стратегического планирования как непрерывного процесса.

Одной из известных и доступных для освоения систем планирования и осуществления связей с общественностью является система RACE, аббревиатуру которого составляют первые буквы английских слов: R - Research (исследование: анализ целевой аудитории, каналов коммуникации, постановка целей и задач), A - Action (действие: разработка конкретных программ и сообщений), C - Communication (общение: обмен ин-формацией, собственно коммуникация), E - Evaluation (оценка: оценка эффективности, внесение корректив) (Von, Petrova, 2015, с. 34).

Наличие коммуникационной стратегии дает возможность установить организационные связи между всеми элементами управления связями с общественностью и направить их в нужном направлении, упорядочить тактические действия. Процессы разработки коммуникационной стратегии (этап A - Action) и реализации связаны с комплексом управленческих операций, среди которых важнейшую роль играют планирование, регулирование изменений и контроль. Фундаментом стратегического планирования коммуникативной деятельности органов публичного управления, в том числе органов правосудия, являются потребности и интересы целевых групп общественности.

Каждая из целевых групп общественности имеет свои интересы, ценностные ориентации, которые необходимо учитывать при стратегическом планировании коммуникативной деятельности суда. По степени важности можно выделить приоритетную или первичную аудиторию (чье общественное мнение имеет наибольшую ценность), вторичную (с менее значимым для организации мнением). Этот процесс называют «ранжированием значимости той или иной группы общественности в жизнедеятельности конкретной организации в отдельный промежуток времени» (Romanovskyi, Sereda, 2015 , с. 39). В процессе определения приоритетов предлагаем составлять «профиль» (характеристику) ценностей каждой из групп целевой аудитории или отдельных индивидов, который будет включать такую совокупность признаков:

- знакомство с работой суда;

- профессиональный статус (должность, особенности профессиональной деятельности); 
- базовые социально-демографические характеристики (пол, возраст, регион проживания, степень образования и т.д.);

- общие ценности целевой аудитории;

- интересы и ценности, важные для коммуникационной деятельности;

- каналы коммуникации, популярные среди целевой аудитории;

- отношение группы общественности к конкретному суда;

- другие характеристики, имеющие важность для установления и поддержания коммуникативного взаимодействия;

- ожидания суда от группы общественности (прогнозирование взаимодействия).

Анализ целевой аудитории с помощью профиля ценностей дает возможность специалисту в области паблик рилейшнз не только эффективно планировать коммуникативные программы, но и действовать в кризисных ситуациях. Итак, в основу реализации коммуникативных стратегий и планов суда должно быть положено понимание общественности как многоструктурное, многофункционального объекта коммуникативной деятельности.

Обобщив вышеизложенное, предлагаем обязательные блоки, которые необходимо предусмотреть в коммуникационной стратегии органа публичного управления, в частности суда:

- общие положения;

- цели, задачи, принципы;

- анализ предпосылок (существующего положения и ресурсов) осуществления коммуникативной деятельности органа власти;

- идентификация целевых групп и определение тематики основных сообщений для каждой из целевых групп [в процессе сегментации сообщений для различных аудиторий также важно сегментировать форму, а не содержание (Yasynevych, 2016, p. 76)];

- определение каналов, средств коммуникации с общественностью;

- определение критериев оценки коммуникативной деятельности, разработка плана действий и мониторинга (Andriiash, Torkhova, 2018, c. 236).

Главным этапом воплощения коммуникационной стратегии суда в жизнь должен стать коммуникационный план (план-календарь) на год. Составление стратегических коммуникативных планов суда целесообразно проводить, учитывая потребность в использовании 
инструментов, определенных в Концепции прямых связей с общественностью (приложение 3 к Меморандуму о взаимодействии и сотрудничестве представителей системы правосудия Украины от 10 февраля 2017 года).

Важной предпосылкой формирования связей с общественностью и элементом стратегического планирования в органах публичного управления является определение приоритетных каналов коммуникации, анализ их инструментов и возможностей воздействия на целевую аудиторию. Стремительное развитие информационного общества требует использования новых коммуникативных форм и активного творческого поиска, направленного на создание уникальных коммуникативных проектов, способных повысить уровень открытости суда для общественности. Распространение практики применения программ охвата (outreach programms) в управленческой деятельности органов правосудия является значительным шагом в имплементации передового зарубежного опыта в деятельность судебной системы Украины. Программы охвата включают широкий круг мероприятий ознакомительного, информативного характера, устанавливают прямую связь между органом власти и общественностью и способствуют получению обществом, на принципах партнерства, информации о деятельности органа.

В судебной системе потребность в преодолении дистанцирования судебной власти от общества обусловила разработку Концепции прямых связей судов с общественностью, в которой впервые был предложен новый подход к информационно-коммуникативной деятельности - формулу прямых связей судов с обществом, которые устанавливаются с помощью программ охвата (outreach programmes).

В Концепции прямых связей судов с общественностью предложены к выбору такие меры / инструменты прямых связей:

- личное общение с судьями и работниками аппаратов судов;

- компьютерные игры;

- мультфильмы (пример - мультфильм «Конь против Хомяка» для учащихся 1-4 классов, который был специально снят в рамках грантового проекта «Повышение осведомленности детей о деятельности судов»);

- фильмы о суде и профессии судьи;

- книги, аудио-книги; 
- видеоблоги (например, «Суд для чайников»);

- инфографика, иконографика;

- спецпроекты (например, «День в суде»);

- ролевые игры;

- посещение суда, судебных заседаний;

- справочники;

- посещение судьями учебных заведений, практические занятия, судебные прения;

- конкурсы;

- долговременные программы привлечения;

- экспертные мероприятия;

- официальные мероприятия;

- лекции;

- интервью;

- дайджесты;

- комментарии;

- блоги, колонки;

- страницы в социальных сетях;

- социальные видеоролики;

- теле / радиопередачи;

- борды (Priami zviazky sudiv z hromadskistiu, 2017, c. 9).

Применение программ охвата вместе с введением должности пресс-секретаря в штатные расписания судов и стратегическим планированием коммуникативной деятельности вызвали изменения, направленные на выход за пределы традиционного информационного взаимодействия суда с общественностью и на переформатирование отношений в векторе партнерства, что положительно влияет на повышение доверия граждан к суду, усиливает независимость судебной власти.

В частности, программы охвата способствуют правильному пониманию функции правосудия населением и ориентированы на конкретную целевую аудиторию граждан, что и предопределяет выбор определенного мероприятия (инструмента прямых связей) для управления общественным мнением и поведением - в этом проявляется сущность управленческой функции связей с общественностью. Важнейшей задачей этой функции является паритетная двусторонняя связь между органом судебной власти и общественностью, компромиссные управленческие решения, касающиеся оптимальной, 
сбалансированной реализации их интересов (Andriiash, Ahafonova, 2018b, c. 214).

Львиная доля программ охвата является универсальной и может быть использована в управленческой и коммуникативной деятельности других органов власти. Реализация прямых инициатив способствует правовой просвещению и воспитанию правовой культуры, а также влияет на возникновение правильного восприятия функции органа власти и формированию его положительного имиджа.

Важность поощрения судебных институтов к активной, «просветительской» роли в информировании общественности была отмечена в Европе еще в 2005 году - в заключении № 7 Консультативного совета европейских судей (КСЕС) по вопросу «Правосудие и общество» ко вниманию Комитета Министров Совета Европы. По мнению КСЕС, изложенного в пунктах 15, 16 Заключения № 7, суды должны действовать также как «спикеры», «посредники» и инициаторы образовательных программ и мероприятий, которые не зависят от деятельности СМИ и/или действий, ответственность за которые возложена на другие учреждения. Рассмотрев имеющиеся в то время прямые инициативы судов по связям с общественностью, КСЕС, кроме общения со СМИ, рекомендовала: создать в органах правосудия отделы, ответственные за прием и информирование граждан; распространять печатные материалы и открыть официальные вебсайты; организовывать образовательные форумы и/или регулярные встречи с гражданами, общественными организациями, политиками, студентами и т.д. («программы охвата») (Andriiash, Ahafonova, 2018a, c. 263).

Организация деятельности по связям органов правосудия с общественностью в развитых странах мира опирается на необходимость практического понимания потребностей общества и тяготеет к управленческой модели, в основе которой лежит стремление сформировать партнерские отношения между общественностью и органом власти. Перспективными направлениями имплементации в Украине мирового опыта управления взаимодействием судов с общественностью также является создание специальных органов для внедрения коммуникативной политики и соответствующих профессиональных организаций, развитие методологии использования программ охвата, использование цифровых и медийных технологий. 
Рост доверия населения к судам (а именно в этом сегодня прежде всего нуждается судебная система Украины), возможно, в частности, благодаря образованию специальных органов, которые обеспечивают связи с общественностью и со средствами массовой информации. В наиболее развитых странах с этой целью создан широкий круг органов, призванных способствовать налаживанию взаимодействия судебной системы с обществом. Основными организационными формами управления связями с общественностью в США и Канаде являются самостоятельные подразделения (службы по связям с общественностью в структуре суда), департаменты, комитеты и т. п. Так, например, в Канаде действует Департамент связей с общественностью, в который входит отдел стратегических коммуникаций и связей со СМИ (Shapoval, Hanha, 2011, с. 30). В задачи этого органа, кроме работы по планированию мероприятий, принадлежит поддержание оперативной связи с другими департаментами и СМИ (для СМИ Департамент является первоисточником объективной информации), обработка общественных запросов.

Эффективное внедрение лучших зарубежных практик управления связями с общественностью возможно после преодоления таких проблем, как недостаток образовательных программ и мероприятий для обучения специалистов по обеспечению связей с общественностью и со СМИ, несовершенство и хаотичность нормативной базы для управления информационно-коммуникативными процессами в органах публичного управления. Так, например, в Украине правовые основы связей органов публичного управления с общественностью закреплены преимущественно в ряде законодательных актов, регулирующих чисто информационную деятельность.

В отношении органов правосудия, реализация функции связей с общественностью и СМИ в судебной системе опирается прежде всего на нормы обнародования информации и установления ограничений в сфере информирования общественности через средства массовой информации. Большую роль в этом процессе играют международные стандарты взаимодействия судов с обществом, в основе которых лежит необходимость соблюдения принципа открытости судопроизводства. Важным правовым основанием управления судами своїй информационно-коммуникативной деятельностью является подзаконные акты, в частности решения Совета судей Украины, принятые в течение 2012-2019 годов. 
В то же время насущной является потребность в правовой регламентации порядка функционирования коммуникационных подразделений органов публичного управления и основ формирования коммуникационной стратегии для органов государственной власти. Наименьший уровень правового регулирования имеет взаимодействие органов власти с общественностью в сети Интернет. Кроме того, на законодательном уровне необходимо принять нормативноправовые акты, в которых будет дано определение понятиям «прессслужба», «связи с общественностью (PR)», «PR-технология», «открытость» и «прозрачность», «коммуникационная стратегия», «судья-спикер» и другие. Ряд международных и действующих ведомственных актов носит рекомендательный характер, что негативно влияет на активизацию деятельности судов по развитию связей с общественностью и СМИ, ее скоординированность и эффективность. Преодоление этой проблемы лежит в плоскости надлежащего законодательного, финансового и научного обеспечения создания диалогового пространства для эффективного взаимодействия судов с общественностью и СМИ.

Новая парадигма связей с общественностью на современном этапе стремится к реализации в форме диалога, к поддержанию в динамике стабильных отношений между государственным учреждением и обществом, которые способны преодолеть негативное общественное отношение к органу власти. Систему связей с общественностью в органе публичного управления представляет собой совокупность взаимосвязанных элементов, которые образуют цепь отношений «власть - общество» с обратной связью. Следовательно, орган власти имеет учитывать важность ориентирования на внешнюю оценку качества своей деятельности. В этом процессе приобретает важное значение применения опрос посетителей суда по методологии карточек гражданской отчетности. В Украине использование карточек гражданского отчетности при взаимодействии судов и общественности введено с 2008 года.

В широком смысле карта гражданской отчетности - это заполненная гражданином анкета, содержащая оценку качества государственных услуг. Это средство для взаимодействия с общественностью, разновидность общественного мониторинга, целью которого является продвижение интересов общества путем выявления имеющихся проблем и слабых мест в деятельности учреждения, повыше- 
ние прозрачности деятельности органа власти. Методология зарекомендовала себя как простой и динамичный инструмент внешнего оценивания, что обеспечивает прозрачность деятельности учреждения. Такая форма взаимодействия с общественностью способствует реализации демократических принципов гласности и открытости, является весомым вкладом в создание положительного информационного поля вокруг органа власти.

Сегодня опросы стали частью национальной системы оценки работы суда, широкое внедрение этой методологии в коммуникативную деятельность других органов власти еще впереди. Самая главная ценность методологии карточек гражданской отчетности заключается в установлении эффективной обратной связи с пользователями услуг органов власти и в возможности привлечь к этому процессу работников этих органов и представителей общественных организаций. Такой подход демонстрирует преобразование информации в управленческие решения, которые реализуются в конкретных действиях по приближению органа власти к обществу, повышению уровня его информационной открытости.

\section{Заключение}

Перспективы функционирования сферы связей с общественностью в органах власти зависят от своевременного понимания необходимости развивать эту управленческую функцию в каждой отдельно взятой государственной структуре. Для создания и функционирования эффективной системы связей с общественностью в органах публичного управления и, в частности, в органах правосудия Украины основными направлениями реформирования этой сферы должны стать:

- формирование единой государственной стратегической информационной политики как на внутреннем, так и в международном пространстве;

- разработка и совершенствование с учетом принципов информационной открытости и прозрачности, нормативно-правовой базы, регулирующей деятельность пресс-служб, структурных подразделений, отвечающих за развитие связей с общественностью в органах государственной власти и местного самоуправления; 
- принятие мер по развитию партнерских отношений между органами государственной власти и средствами массовой информации, с целью преодоления недоверия граждан к власти;

- организация изучения лучших мировых практик интеграции органов власти в жизнь общества и внедрение инновационных инструментов построения и реализации коммуникативной политики государственных структур, в частности программ охвата;

- организация проведения исследований с целью изучения и прогнозирования эффективности использования инновационных инструментов взаимодействия пресс-служб с общественностью;

- активизация обратной связи с общественностью путем налаживания процесса проведения опросов граждан-посетителей органов государственной власти;

- разработка системы качественной оценки эффективности работы пресс-служб в органах власти и повышение уровня выполнения нормативно-правовых актов, регламентирующих обеспечение открытости и прозрачности органов власти;

- использование новейших информационных технологий и возможностей сети Интернет для содействия двустороннему диалогу между гражданами и властью, внедрение стандартов освещения деятельности органов власти в интернете;

- разработка и внедрение учебных программ по вопросам коммуникации с общественностью для управленцев всех уровней в органах государственной власти; разработка образовательных мероприятий для теоретической подготовки работников прессслужб в органах власти;

- создание специальных органов для внедрения коммуникативной политики и соответствующих профессиональных организаций. Перспективы дальнейших исследований заключаются:

- в комплексном исследовании теоретических и прикладных аспектов управления информационно-коммуникативной деятельностью органов судебной власти, с целью разработки эффективных технологий взаимодействия судов с общественностью;

- в исследовании отдельных этапов разработки и реализации коммуникационных планов для выбранных групп общественности;

- в исследовании методов создания партнерских отношений между органами публичного управления, в частности органами правосудия, и общественностью. 


\section{Библиография}

Агафонова Н. (2018), Сутність зв'язків з громадськістю в системі публічного управління Ahafonova $N$., „Публічне управління та регіональний розвиток”, № 1, с. 10-31, doi: https://doi.org/10.26693/pard2018.01.02.

Андріяш В. І., Агафонова Н. О. (2018), Сучасні підходи до трансформації управління зв'язками з громадськістю в органах правосуддя. Problems and Prospects of Territories 'Socio-Economic Development: матеріали VII Miжнародної наукової конферениії (м. Ополє, Польщза, 4-7 квітня 2018 року), The Academy of Management and Administration, Opole, c. 263-265.

Andriiash V., Ahafonova N. (2018), Direct public relations as a part of the management process in the judiciary of Ukraine. Proceedings of the international scientifi c conference economic and social-focused issues of modern world, The School of Economics and Management in Public Administrationin Bratislava, Bratislava, pp. 211-215 (in English).

Андріяш В. І., Торхова Н. О. (2018), Комунікаційна стратегія як інструмент формування зв 'язків з громадськістю у сфері публічного управління: особливості застосування в органах правосуддя, „Публічне управління та регіональний розвиток”, № 2, с. 217-238, doi: https://doi.org/10.26693/ pard2018.02.217.

Архипова С. О., Дмитренко Н. О. (2016), Ефективна комунікація між органами державної влади та громадськістю як умова розвитку демократичного суспільства, „Інвестиції: практика та досвід”, № 1, с. 92-66.

Вільгушинський М. Й. (2014), Взаємодія судів із засобами масової інформації в аспекті інформування громадськості про стан здійснення судочинства, „Адвокат”, № 3 (162), с. 5-8.

Звіт за результатами дослідження «Ставлення громадян України до судової системи»: інфографіка (2019), Український центр економічних і політичних досліджень імені Олександра Разумкова, Київ, 52 с., http:// razumkov.org.ua/uploads/socio/Infographics_2019_02.pdf, 17.08.2019.

Зв'язки із громадськістю в судах: навч.-практ. посіб. для суддів і працівників anapamy судів (2015), Д. Вон та ін., ТОВ «Друкарня «Бізнесполіграф», Київ, 232 с.

Прямі зв'язки судів з громадськістю. Методичні рекомендаиії: збірник документів і статей (2017), Прецедент, Київ, 136 с.

Рейтинг інформаційної відкритості судів. Майданчик правничих комунікацій (2019), http://faircourt.in.ua/news/180220191852.html, 17.08.2019.

Романовський О. Г., Середа Н. В., Воробйова Є. В. (2015), Основи паблік рилейшнз: навч.-метод. посіб. для студентів спеціальностей 8.03010201 «Психологія» та 8.18010018 «Адміністративний менеджмент», НТУ «ХПІ», Харків, 176 с.

Торхова Н. О. (2018), Напрями реформування сфери зв'язків з громадськістю в органах публічного управління в Україні. Science and Technology of the 
Present Time: Prority Development Directions of Ukraine and Poland: $\mathrm{ma-}$ теріали Міжнародної мультидисциплінарної конференцї (м. Воломін, Польщиа, 19-28 жовтня 2018 року), Baltija Publishing, Wolomin, c. 56-58.

Шаповал А., Ганга В. (2011), Міжнародний досвід вісвітлення кримінального та циивільного судочинства, „Віче”, № 8, с. 30-32.

Ясиневич Я. Я. (2016), Комунікація громадських ініціатив. Для тих,хто творить зміни. Практичний посібник, Інститут масової інформації, ТОВ «Софія-А», 104, , Київ.

\section{Bibliography}

Ahafonova N. (2018), Sutnist zviazkiv z hromadskistiu v systemi publichnoho upravlinnia [The essence of public relations in the public administration], „Publichne upravlinnia ta rehionalnyi rozvytok”, nr 1, pp. 10-31, doi: https:// doi.org/10.26693/pard2018.01.02.

Andriiash V. I., Ahafonova N. O. (2018a), Suchasni pidkhody do transformatsii upravlinnia zviazkamy $z$ hromadskistiu $v$ orhanakh pravosuddia [Current approaches to the transformation of public relations management in the judiciary], „Problems and Prospects of Territories Socio-Economic Development": Proceedings of the VII International Scientific Conference (Opole, Poland, April 4-7, 2018), The Academy of Management and Administration, Opole, pp. 263-265.

Andriiash V.,Ahafonova N. (2018b). Direct public relations as a part of the management process in the judiciary of Ukraine, Proceedings of the international scientific conference economic and social-focused issues of modern world, The School of Economics and Management in Public Administrationin, Bratislava, pp. 211-215.

Andriiash V. I., Torkhova N. O. (2018), Komunikatsiina stratehiia yak instrument formuvannia zviazkiv $z$ hromadskistiu u sferi publichnoho upravlinnia: osoblyvosti zastosuvannia v orhanakh pravosuddia [Communication strategy as a tool for public relations in the field of public administration: peculiarities of application in the judiciary], „Publichne upravlinnia ta rehionalnyi rozvytok", no. 2, pp. 217-238, doi: https://doi.org/10.26693/pard2018.02.217.

Arkhypova Ye. O., Dmytrenko N. O. (2016), Efektyvna komunikatsiia mizh orhanamy derzhavnoi vlady ta hromadskistiu yak umova rozvytku demokratychnoho suspilstva [Effective communication between public authorities and the public as a condition for the development of a democratic society], „Investytsii: praktyka ta dosvid", no. 1, pp. 92-66.

Priami zviazky sudiv z hromadskistiu [Direct communication of courts with the public], (2017), Pretsedent, Kyiv.

Reitynh informatsiinoi vidkrytosti sudiv [Rating of information openness of courts] (2019), http://faircourt.in.ua/news/180220191852.html. 
Romanovskyi O. H., Sereda N. V., Vorobiova Ye. V. (2015), Osnovy pablik ryleishnz [Basics of public relations], NTU „KhPI”, Kharkiv.

Shapoval A., Hanha V. (2011), Mizhnarodnyi dosvid visvitlennia kryminalnoho ta tsyvilnoho sudochynstva [International experience of coverage of criminal and civil proceedings], ,Viche”, no. 8, p. 30-32.

Torkhova N. O. (2018), Napriamy reformuvannia sfery zviazkiv z hromadskistiu $v$ orhanakh publichnoho upravlinnia $v$ Ukraini [Areas of public relations reform in public administration in Ukraine], Science and Technology of the Present Time: Prority Development Directions of Ukraine and Poland: Proceedings of the International Multidisciplinary Conference (Wolomin, Poland, October 19-28, 2018), Baltija Publishing, Wolomin, pp. 56-58.

Vilhushynskyi M. Y. (2014), Vzaiemodiia sudiv iz zasobamy masovoi informatsii $v$ aspekti informuvannia hromadskosti pro stan zdiisnennia sudochynstva [Interaction of courts with the media in terms of informing the public about the status of judicial proceedings], ,Advokat”, no. 3 (162), pp. 5-8.

Von D., Petrova N., Filipenko D., Mukhin Yu., Soldatenko I., Zemlianoi V. (2015), Zviazky iz hromadskistiu v sudakh [Public relations in courts], Printing House „Biznespoligraf” Ltd., Kyiv.

Yasynevych Ya. Ya. (2016), Komunikatsiia hromadskykh initsiatyv. Dlia tykh, khto tvoryt zminy [Communication of community initiatives. For those who create change], TOV „Sofiia-A”, Kyiv.

Zvit za rezultatamy doslidzhennia ,Stavlennia hromadian Ukrainy do sudovoi systemy": infohrafika [Report on the results of the survey „Attitudes of Ukrainian citizens in the judicial system": infographic] (2019), The Ukrainian Center for Economic and Political Studies named after Oleksandr Razumkov, Kyiv, http://razumkov.org.ua/uploads/socio/Infographics_2019_02.pdf.

\section{Management of public relations in the courts of Ukraine as a multifaceted complex process}

\section{Summary}

The article explores the theoretical and practical foundations of public relations management in courts of Ukraine, courts which need to increase the level of trust among citizens and become more transparent in the context of reforms. The author deals with public relations management in the Ukrainian judiciary as a multifaceted complex process which includes the setting up of a communication unit and training of its employees, identifying the needs of target groups of the public on the basis of a value profile design, strategic planning of communication activities, the use of relevant programs and methodologies of civil reporting. The article defines the concept of public relations in the judiciary taking into account the specific features of the judicial system. It diagnoses problems in the field of public relations in the judicial system 
and provides recommendations for creating an effective system of public relations in the public administration.

Key words: management, court, public relations

\section{Zarządzanie public relations w sądach Ukrainy jako proces wieloaspektowy}

\section{Streszczenie}

Artykuł analizuje teoretyczne i praktyczne podstawy zarządzania public relations w sądach Ukrainy. Autor podkreśla zarządzanie public relations w sądownictwie ukraińskim jako wieloaspektowy złożony proces, który obejmuje organizację jednostki komunikacyjnej i rozwój umiejętności jej pracowników, identyfikację potrzeb grup docelowych społeczeństwa na podstawie profilu wartości, strategiczne planowanie działań komunikacyjnych, stosowanie programów informacyjnych i metodologii kart raportowanie cywilne. Artykuł formułuje definicję pojęcia public relations w sądownictwie z uwzględnieniem specyfiki wymiaru sprawiedliwości, diagnozuje problemy w zakresie organizacji public relations w sądownictwie, podaje rekomendacje dotyczące stworzenia skutecznego systemu public relations w organach publicznych.

Słowa kluczowe: zarządzanie, sąd, public relations 